\title{
DISCURSO DE AGRADECIMENTO*
}

http://dx.doi.org/10.11606/issn.2237-1184.v0i33p216-227

Davi Arrigucci Jr. ${ }^{\mathrm{I}}$

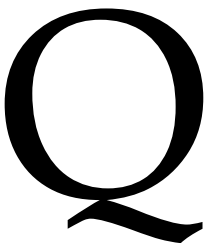

ueridos alunos e ex-alunos, queridos amigos, senhoras e senhores:

Durante todo o tempo que precedeu esta cerimônia, desde o anúncio da entrega deste título, procurei driblar, de diversos modos, a emoção; espero poder driblá-la de novo agora, por meio da palavra escrita e da leitura. Como sabem meus alunos, não costumo escrever o que falo, mas me senti obrigado a fazê-lo, a fim de domar o que talvez não pudesse conter.

Para não me perder, ao sentir o pensamento tomado pela emoção, busquei a lição da disciplina mental de Fernando Pessoa/Ricardo Reis:

Sê todo em cada coisa. Põe quanto és

No mínimo que fazes.

O que vão ouvir é o resultado desse esforço.

Gostaria de agradecer muito a muitos e, ao mesmo tempo fazer um rápido depoimento, misturado à memória e à reflexão, sobre a natureza de meu trabalho e como o vejo nos dias de hoje: uma ocasião como esta nos coloca diante do espelho.

Vou tentar ser breve; há muito a velha fórmula de Baltasar Gracián para o estilo conceptista do barroco - excesso resumido - se tornou para mim um lema: "Lo breve, si bueno, dos veces bueno; lo malo, si breve, menos malo". Mas mesmo a brevidade depende da escala do que se tem para dizer, e lhes peço paciência para o que passar da conta.

Desejo agradecer, em primeiro lugar, a meus ex-alunos cuja generosidade me trouxe até aqui. Muitos são hoje meus colegas, quando

* Discurso pronunciado na cerimônia de outorga do título de Professor Emérito da Faculdade de Filosofia, Letras e Ciências Humanas da Universidade de São Paulo, em 19 de maio de 2011.

I Universidade de São Paulo, São Paulo, São Paulo, Brasil. 
não companheiros do Departamento de Teoria Literária e Literatura Comparada - uma de minhas orientandas é mesmo Diretora desta Casa. Quando digo Casa, no entanto, penso na que ficava na Rua Maria Antônia onde ingressei ainda menino e mudou minha vida. Eram outros tempos, de muito fervor, muita agitação política e um horizonte de promessas, antes do golpe de 64. Ali me formei e tive minhas primeiras grandes turmas de alunos. Muitos me acompanharam ao longo dos anos; alguns se acham aqui, como nossa Diretora. Os demais andam dispersos pelo mundo; vários se dedicaram às letras como professores universitários, críticos e escritores. E outros se foram muito cedo, como Lúcia Teixeira Wisnik, João Luiz Lafetá, José Luiz Beraldo, Heitor Ferreira, Tânia Carvalhal, Haquira Osakabe... Sei, porém, que posso imaginá-los aqui presentes. É este um dos dons da imaginação: o de criar símbolos que povoam os espaços da ausência.

Por isso, gostaria de evocar outros ausentes, para também a eles agradecer. Meus pais, que estiveram nesta sala em outros momentos de minha carreira e teriam gostado de ver aonde foi dar o caminho que o filho escolheu e eles tenham talvez hesitado em aceitar, tornando-o possível, mesmo assim, com seu trabalho e afeto. Nossos pais costumam ser nossos primeiros professores, às vezes receosos e desajeitados; a verdade é que devo aos meus o que para mim se tornou essencial: o gosto da leitura. Meu pai, médico ocupadíssimo, de vez em quando se trancava no banheiro para ler Dostoiévski. Minha mãe, que viveu 97 anos, foi uma leitora contumaz e só desistiu dos livros, quando perto da morte desistiu também do mundo: recolheu-se, de novo menina, na casa da fazenda Campo Triste que já não existia mais, com os entes queridos de sua infância.

Depois vieram os professores efetivos: Francisco Pachoal, professor de Português, que ainda moço dera aulas também a Antonio Candido, de quem guardava com carinho o primeiro artigo escrito para um jornal de São João da Boa Vista aonde seu ex-aluno de Poços de Caldas viera cursar o ginásio. Em seguida, Américo Casellato, que ensinava Latim, mas era homem de sete instrumentos: cozinheiro, criador de porcos e bezerros, enxadrista, leitor dos clássicos e de romances policiais, apaixonado por Vivaldi e orquídeas, pescador, filósofo nas horas vagas. Esse homem inumerável era capaz da maior concentração diante de um texto latino, cujas dificuldades, para meu espanto, resolvia entre idas e vindas ao fogão e uma mexida nas panelas.

Por fim, o Dr. Joaquim José de Oliveira Neto, grande mestre oral, que sabia resumir de tudo um pouco no encanto da conversa e formara uma extraordinária biblioteca, cujas portas generosamente me abriu. Antonio Candido sempre diz que foi um dos três maiores professores que conheceu. Para mim, ainda muito jovem, creio que propiciou o reconhecimento do livro como objeto e símbolo. Algo que pode ser bonito em si mesmo e ao mesmo tempo um instrumento da memória e da imaginação, a que se 
refere Borges. Sobretudo, naquele tempo, um objeto mágico para o menino que pôde descobrir em sua caixa de segredos a neblina de Diadorim e mundos e fundos da literatura.

Vim do interior à rua Maria Antônia para estudar Línguas Neolatinas, obedecendo ao que julguei ser uma vocação filológica. Penso que ela se acha na base do que faço até hoje, mas disso pretendo falar mais adiante. Meu mestre de Filologia Românica, com seu método históricocomparativo foi o Prof. Isaac Nicolau Salum, homem minuciosíssimo, de vasta erudição clássica, rigorosa lente analítica e espaçosa prosa mineira. Nos trabalhos que pedia era estrito: apenas cinco páginas, não importando o tamanho da letra (era afeito à lupa e aos manuscritos ilegíveis), escritas de um lado só da folha, que o avesso ficava para seus comentários. Num trabalho meu sobre a oração infinitiva no latim clássico, no latim vulgar e nas línguas românicas, pôs 79 notas escrupulosíssimas. Nunca vi nada tão bem corrigido. Mas Salum gostava mesmo era de prosear, contando casos e curiosidades do Sul de Minas onde nascera; e conversava com qualquer um, sem distinção. Talvez gostasse de saber quão valioso foi para mim seu legado: a saborosa mistura de filologia homérica com linguiça e couve à mineira.

Desde pequeno descobri, pelo prazer que sentia lendo, que meu destino seria o das Letras: pensava em ser escritor, mas sabia muito bem que um escritor não se forma na escola - "ninguém aprende samba no colégio" -, pois o ato de escrever depende de muita coisa na vida, de uma experiência que se alimenta dos livros, mas também do trato com os homens e dessa lenta assimilação do vivido que é tão difícil de definir como tantas coisas fundamentais em nossa relação com o mundo e suas mudanças. Ser professor ou uma espécie de filólogo me pareceu razoável como profissão, já que não poderia ganhar a vida escrevendo. Escolhi assim não um destino épico, mas simplesmente um de trabalhador das letras. E na Maria Antônia me formei.

Seria longo, complicado e decerto aborrecido relatar o processo de minha formação ou de minha trajetória intelectual - cujos pontos principais, aliás, Fábio de Souza Andrade já referiu com precisão. Nem mesmo vou me deter nas questões teórico-críticas de que me ocupei ao longo dos anos, como as da forma mesclada e das relações entre literatura e experiência histórica no contexto brasileiro ou hispano-americano, a que tenho dedicado meu esforço crítico. Gostaria apenas de agradecer a alguns professores e alguns interlocutores que tive nesses anos e que me acompanharam depois e sempre como figuras intelectuais com as quais dialogo todo o tempo e que vou tomar mais uma vez simbolicamente, como representantes de todos os demais que não posso nomear e de tudo quanto ali vivi e aprendi. Sem essas pessoas não seria o que sou e o que a elas devo é muito mais do que aqui posso exprimir e agradecer. E que não se culpe nenhum deles pelo resultado. Refiro-me a Décio de Almeida 
Prado, Antonio Candido, Gilda de Mello e Souza, Alfredo Bosi e Roberto Schwarz.

Não vou dar muitos detalhes de cada um, pois são figuras por demais conhecidas. Limito-me ao que der para o gasto. Comecei a escrever pelas mãos de Décio no Suplemento Literário do Estado de S. Paulo, nos meados da década de 1960; depois foi meu professor de teatro na Faculdade: falava de pé, ao lado da mesa (folheando cadenciadamente um bloco sem pauta em que não lia), sem perder o fio do assunto, com a naturalidade, a elegância e a verve com que conversava, entremeando seriedade e sorrisos de fina ironia, na medida certa, mas que eram as mesmas e inacreditáveis qualidades com as quais escrevia, com as quais escreveu essa obra espantosa sobre espetáculos, dramaturgos, atores, coisas, pessoas e futebol e a história do teatro brasileiro que foi estendendo no papel à medida que envelhecia feito vinho bom, capaz de mostrar a que veio ao ser aberto.

Comecei, mocinho, lendo a crítica brasileira: sobretudo, Mário de Andrade, Augusto Meyer, Lúcia Miguel Pereira, Álvaro Lins, Otto Maria Carpeaux, Antonio Candido. Já vinha lendo, portanto, Antonio Candido quando o conheci pessoalmente, creio que em 1963, levado pelo Dr. Oliveira Neto, com quem fui visitá-lo na sala de Teoria Literária e Literatura Comparada, na ala direita do edifício da Faculdade na Maria Antônia, a mesma salinha onde, a partir de 1968, iria trabalhar com ele, com Roberto Schwarz, Walnice Nogueira Galvão e um pouco mais tarde, também com João Alexandre Barbosa e Teresa Pires Vara. Lembro-me de que Antonio Candido vestia o paletó de lã do Sul de Minas tão característico dele e nos recebeu com muitas gentilezas e lembranças de $\mathrm{S}$. João e Poços de Caldas. Na saída, Oliveira Neto se referiu à série de artigos que Wilson Chagas estava publicando ou acabara de publicar no Suplemento Literário do Estadão sobre a Formação da literatura brasileira. Ao que Antonio Candido respondeu: - "Está me pondo num torniquete". E sorriu.

Assim começou para mim uma história que se transformou, a partir de 1968, em colaboração e fértil diálogo intelectual e numa constante e afetuosa amizade. Dela compartilhou também Gilda de Mello e Souza, que me acompanhou com a leitura das obras de Julio Cortázar durante todo o percurso de elaboração de meu livro sobre ele, demonstrando a cada passo as qualidades da refinada e entusiasmada leitora que era, da intérprete imaginativa que sabia mover-se por um agudo senso da forma estética e da percepção do valor.

A primeira imagem que trago comigo de Alfredo Bosi, meu jovem professor de italiano, assistente do inesquecível Professor Italo Bettarello, e meu fraterno companheiro de viagem durante a vida toda - Alfredo esteve na banca examinadora de todos os passos de minha carreira - é a de vê-lo escrevendo na lousa a frase "Arte è espressione", Benedetto Croce, e 
depois pedir-nos que a comentássemos em função de uma página famosa de I promessi sposi, de Alessandro Manzoni, quando se dá o encontro entre Renzo e Lucia, depois da chuva. Não consigo imaginar como saí da enrascada de escrever em italiano o que mal podia formular em português. O fato é que Bosi me abriu o universo da literatura italiana e de sua crítica, do qual nunca mais saí, sobretudo quando o fascínio, atiçado decerto pela curiosidade em saber a história dos Arrigucci, se estendeu de Dante à crítica de arte.

Conheci Roberto Schwarz num ciclo de conferências sobre o romance brasileiro, quando ele veio falar sobre o "O Ateneu" e tive de fazer as honras da casa no antigo Instituto de Cultura Hispânica de S. Paulo onde era meu gabinete de trabalho como assistente de espanhol da Faculdade, vizinho, aliás, de Modesto Carone, que na sala ao lado nessa época falava alemão. Nunca me esquecerei do olhar assanhado das meninas, saídas candidamente em uniforme escolar das aulas da tarde para ouvir $o$ conferencista, que permanecia em silêncio, só quebrado por alguma tosse e rangidos das cadeiras, até que disse afinal: - "O Ateneu é um livro sórdido". Depois de alguns meses de convivência como colegas na Teoria Literária durante os anos de 68 e 69, quando Roberto teve de deixar o país e foi para a França, começamos uma correspondência, até que o reencontrei em Paris em 1975 e passamos mais de um ano conversando, praticamente todos os dias. Nasceu entre nós uma amizade fecunda, que é das coisas mais importantes de minha vida. Com todas as divergências, que são muito menores que nossas afinidades, Roberto é para mim o exemplo máximo de como a crítica, conforme disse Machado de Assis em seu "Ideal do crítico", em 1865, deve se desenvolver, com toda a franqueza e autonomia, em meio à urbanidade das relações, estabelecendo uma ponte viva entre a esfera dos problemas intelectuais e das preocupações estéticas e o universo da sociabilidade humana. A amizade também pode se enriquecer com as contradições. Neste caso, como lembra Benjamin, convencer é infecundo.

Conforme disse outras vezes, todo o meu trabalho nos estudos literários - aulas, conferências e ensaios - tem a ver com a teoria e a prática da interpretação. Comentar, analisar e interpretar os textos são as operações fundamentais e entrelaçadas que constituem a leitura crítica. A ela me dediquei no começo de meu curso na Maria Antônia, quando procurei um caminho para o entendimento das obras literárias que desde o primeiro momento tinha de analisar, sem que houvesse uma direção clara para tanto. Por onde começar? Essa questão - "Par où commencer?" a que Roland Barthes daria a resposta da análise estrutural nos anos de 1970, se colocou para mim como uma questão prática imediata no início da Faculdade, no princípio da década anterior. Nesses anos a corrente crítica em voga era a Estilística. As leituras que fiz então de Erich Auerbach, Leo Spitzer e Dámaso Alonso foram para mim decisivas, pois me permitiram 
expandir o núcleo de minha formação filológica na direção da obra de arte literária e do ensaio crítico. A leitura da "Introdução" da Formação da literatura brasileira e o exame da prática analítica de Antonio Candido nos textos e nas aulas me deram o empurrão definitivo no mesmo rumo. A essa base fui somando muitas outras leituras: do marxismo (Lukács, Benjamin e Adorno), da psicanálise (Bachelard, Ricoeur), das tentativas de integrar estilística, sociologia e psicanálise (Starobinski); de Eliot e da Nova Crítica anglo-americana (Empson, Brooks, Blackmur), do formalismo russo...

Foram anos de muito estudo e, como diria meu querido amigo Sergio Miceli, derrubei as estantes. Mas o mais importante de tudo isso é o que realmente fica, o que vai se depurando com o tempo e se cristaliza numa atitude crítica pessoal diante da obra, quase uma marca da personalidade que se traduz num modo de ler particular e até certo ponto único, que se singulariza ainda mais nos traços do estilo, com sua aliança misteriosa de determinações biológicas e culturais, quando se transfunde em escrita.

Decifrar, imaginar, escrever são, para mim, três ações que se coadunam na configuração da forma do ensaio. Penso que a crítica é uma fantasia inspirada que nasce pelo estímulo da obra como uma imitação imaginária, através da qual se deve revelar a lógica de construção do todo e a razão da inesgotabilidade de seu sentido enquanto símbolo. Toda obra tem caráter enigmático e nos desafia à interpretação. Como disse o saudoso poeta Cacaso: "Todo objeto é enigma; todo pensamento, comentário". Quanto mais exata for a fantasia, mais próximos estaremos do limiar de uma revelação, que é o instante da percepção estética, a que nos conduz o caráter enigmático da obra à medida que se deixa decifrar. $\mathrm{O}$ ensaio é o exercício dessa tentativa de aproximação: tateio sobre o enigma, até o limite do insondável.

Interpretar, decifrar, exige imaginação. Isso significa que a imaginação é, segundo penso, tão essencial para a crítica quanto para um poema ou uma narrativa. Ela já se mostra como um ingrediente na percepção do objeto, mesclada à intuição: ao ler um texto intuímos obscuramente o que significa, mas é a imaginação que nos antecipa o sentido do todo, que nos permite adentrar o mistério pela sugestão das imagens que nos adianta. Pode nos conduzir ao erro, mas quando lastreada pela solidez do comentário filológico, limitada pelo saber linguístico e histórico, é segura e indispensável companheira. Mas a imaginação se mistura também à memória, que ela ao mesmo tempo evoca e transforma: sendo ela própria uma espécie de memória transformada. Está por fim na forma da escrita do ensaio que ela ajuda a plasmar e afinar, como um instrumento revelador.

Desde o começo percebi que a importância do comentário filológico ia além da mera preparação do terreno para a interpretação. No meu modo de ver, ele é mais do que um simples esclarecimento do que é possível 
explicar para a penetração na estrutura significativa que constitui o alvo da compreensão. Misturando-se com a análise, cujos primeiros passos ele facilita, na verdade, mediante a intuição e a imaginação, acumula dificuldades para melhor superá-las, sendo um instrumento dialético e uma antecipação estratégica dos problemas que constituem o núcleo resistente ao entendimento e à sua tradução em palavras, que é a interpretação. Como um narrador, o crítico, enquanto comentador, não deve perder palavra e jamais estender-se em explicações inúteis. Seu lema deve ser sempre a exatidão (igual, aliás, ao do cozinheiro, segundo BrillatSavarin). Ao parafrasear um texto como meio de organização da matéria em que deve penetrar, mesmo quando parece desgarrado em aparente circunlóquio, já deve estar conduzindo quem o lê ao coração do problema. Exatamente como o narrador que vence por pontos o leitor desprevenido, o qual, esperando ser abatido por nocaute, é desviado pela aparente desconversa de ameaças laterais, mas na verdade já está sendo minado pelos golpes sorrateiros e precisos que por fim e inapelavelmente o vencerão. $\mathrm{O}$ perfeito comentário, imprescindível como conhecimento prévio que nos desvia dos escolhos capazes de barrar a penetração é, portanto, ainda mais: uma leitura narrada com a qual se constrói a fantasia exata do texto, o que nos permitirá o descortino de seu modo de ser e a regra secreta de sua construção. Diante do enigma, sempre é possível ensaiar um comentário.

O último poema da Lira dos cinquent'anos, de Manuel Bandeira, denominado "Carta de brasão" parece hermético e impenetrável:

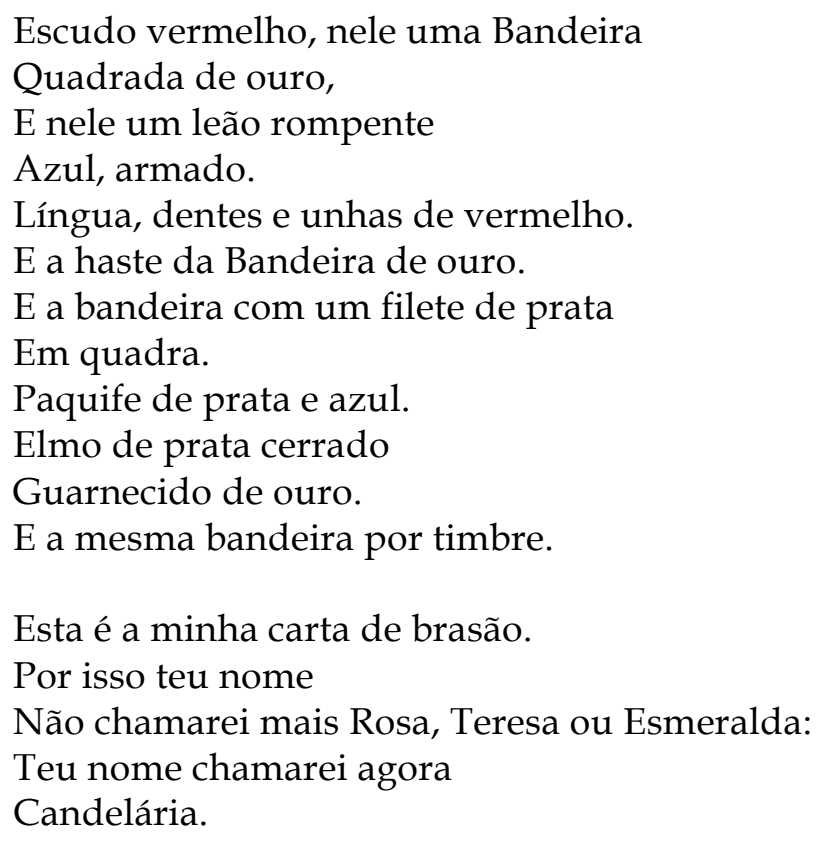

22-6-1943.

Meses atrás, Antonio Candido chamou minha atenção para o que lhe parecia um erro tipográfico no terceiro verso, que poderia ter se perpetuado ao longo dos anos e das diferentes edições, até a última que o 
poeta reviu em vida, A estrela da vida inteira, de1966: em lugar de "nele" deveria ser, segundo observava, "nela", concordando com a "Bandeira quadrada" em cujo interior estaria o "leão rompente", isto é, erguido sobre as patas traseiras. À primeira vista, me pareceu lógico e concordei com ele; ao me deter, porém, no poema como um todo, mudei de opinião. Creio que só o comentário de toda a composição permite ver que o texto está correto e que nos desafia com um notável enigma.

O poema é composto de duas estrofes irregulares de versos livres: a primeira com 12 versos e a segunda com 5. Trata-se basicamente de um poema imagético ou pictórico, poesia que lembra a pintura, em cuja primeira parte vem descrito o escudo da família Bandeira, mediante figuras, ornatos e cores apresentados com termos precisos de heráldica. A segunda, após resumir essa descrição como a carta familiar do poeta que nos fala, misteriosamente vincula a ela - "Por isso teu nome..." - o processo de nomeação de uma mulher.

Que mistério permite ligar a figuração que representa o nome do poeta ao nome de uma mulher? Seria esse belo e luminoso nome, Candelária, o da amada? Os nomes que, segundo o texto, não convêm a ela são todos eles de seres caros ao poeta como se vê pelos poemas em que aparecem Rosa, Teresa e Esmeralda. Esconde o secreto vínculo entre os nomes um disfarçado jogo erótico? A rigor, no conjunto, estamos diante de um duplo processo de nomeação, posto em paralelo, seguido de uma misteriosa ligação final entre os nomes (o sobrenome do poeta e o prenome da amada).

Numa excelente análise da poesia de Mário de Andrade, Gilda de Mello e Souza analisa de passagem esse poema de Bandeira, comparandoo ao poema "Brasão" de Mário, escrito bem antes, em 1937. Destaca especialmente, na primeira parte, a secura e a frieza heráldica da descrição geometrizante de Bandeira, à maneira descarnada da pintura moderna, na qual ressaltaria apenas um "fortuito trocadilho entre o timbre do brasão e o sobrenome do poeta", em contraste com a profusão imagética, oblíqua e cheia de segundas intenções do "Brasão" de Mário. Observa então, com agudeza, na segunda estrofe bandeiriana, um fecho imprevisto diante da simplicidade enxuta e da frieza do início: uma rendida deposição de armas por parte do poeta aos pés da amada. Creio que a intuição de Gilda guarda profundas reverberações que o comentário mais desenvolvido permite compreender em camadas ainda mais secretas e surpreendentes.

Quando se atenta para a construção da primeira estrofe, verifica-se que ela obedece a uma enumeração paralelística, por vezes anafórica, pela repetição dos mesmos termos iniciais, sobretudo a conjunção aditiva $e$, como no caso da expressão que suscitou a dúvida de Antonio Candido: " $E$ nele". Esta repete, na verdade, o padrão anterior, reiterando o esquema construtivo do princípio do poema. As figuras vão se encaixando num mesmo modelo, com independência, formando um paralelismo regido 
pela simples coordenação dos termos que o constituem e funcionam como frases autônomas. Toda a construção é paratática: não há verbos nem subordinação, e as imagens parecem boiar suspensas no branco da página, dispostas como figuras e cores no espaço, em áspero recorte geométrico e contrastante, como nos quadros cubistas.

Essas florações imagéticas que se estampam no espaço da página mantêm, no entanto, entre si a relação oculta de uma história lacunar, cujos elos, numa elipse mental, o poeta guardou em segredo. Trata-se da história que converteu o simples nome comum de um objeto, a bandeira (com minúscula, como vem grafada duas vezes), no nome próprio de uma família, Bandeira (com maiúscula, como vem grafada também duas vezes). As figuras da heráldica convertem-se, por esse procedimento, em metonímias de uma realidade histórica soterrada, que é preciso desentranhar do passado perdido para que faça sentido o processo de nomeação a que elas aludem.

Com efeito, quando se investiga a origem do sobrenome Bandeira, codificada na carta de brasão, ficamos sabendo que foi Gonçalo Pires Juzarte da Bandeira o primeiro a usar esse sobrenome. Na batalha de Toro (em março de 1476), sendo escudeiro de Gonçalo Vaz Pinto, conseguiu recuperar a bandeira real que os portugueses, sob o comando do príncipe herdeiro (o futuro D. João II de Portugal), deixaram cair em mãos das forças de Castela e Aragão. Esse feito, somado a outros serviços que prestara na costa do Marrocos, fez com que seu senhor, depois de alçado ao trono, o elevasse à nobreza, conferindo-lhe o sobrenome Bandeira em homenagem ao ato heróico que praticara.

A linda palavra Candelária, feita de fogo e luz, já que remonta ao latim candela, que significa vela, designa também a santa conhecida pelos nomes de Nossa Senhora da Luz ou das Candeias. E também por Nossa Senhora da Purificação, cuja devoção remonta ao episódio da história sacra da apresentação de Jesus no Templo: aquela que pode purificar feito o fogo. O seu nome, como o sobrenome Bandeira, tem sua parte decisiva velada no poema: a Virgem Candelária teria feito sua primeira aparição por volta de 1400, em Tenerife, nas Canárias, onde os nativos, encadeados por seu fulgor ficaram paralisados de medo, e seu culto teria se firmado em Portugal desde o século XV, exatamente na mesma época histórica da origem do sobrenome Bandeira.

Assim, fundadas no paralelismo entre as estrofes, as histórias paralelas e secretas dos nomes criam a base para o encontro aparentemente arbitrário e fortuito dos amantes que acabam por se vincular, soldados mediante as palavras que os nomeiam, na unidade simbólica do poema que conta sua história ao mesmo tempo velada e luminosa, oculta e clara, perdida e reencontrada através dos nomes Bandeira e Candelária. No amor, encontro fortuito, o acaso se faz destino. Na poesia, as palavras e os seres que elas evocam tendem a se reunir em estreita unidade pela força da 
simples nomeação. Um encontro encantatório de vocábulos define, segundo Bandeira, o modo de ser das imagens poéticas e de seu fulgurante mistério, como unidades do sentido e da reconciliação dos opostos a que o ritmo dá movimento, integrando-as no todo do poema, símbolo final em que o mais separado e contraditório se pode juntar. $O$ poema enlaça os amantes.

"Carta de brasão" pode ser lida, portanto, como uma composição, parecida à pintura, sobre ato fundador da poesia que é o ato de dar nome às coisas e aos seres, amorosamente vinculados pelo enlace das palavras na unidade do poema, como figuras, linhas, cores e volumes se integram na unidade de um quadro. É pela força imaginária do nome, daquilo que pode ser, que a poesia instaura seu reino. Reino da imaginação em que se projetam possibilidades de ser através das imagens. "A hipótese da imagem é a possibilidade", afirmou o grande poeta cubano Lezama Lima, e o poema de Bandeira o demonstra.

O comentário, embora sumaríssimo, nos permitiu vislumbrar, para além da explicação dos obstáculos ao entendimento do texto, o segredo maior do poema que ao dar nome inventa outro ser e outros possíveis, que podem ou não corresponder à realidade da história, mas sempre serão hipóteses de ser, como se fossem realmente.

Por fim, é preciso acrescentar que na mudança da primeira para a segunda estrofe, se dá o movimento de estilo característico de Manuel Bandeira. Como bem intuiu Gilda, há uma espécie de deposição de armas aos pés da amada. A meu ver, ocorre aí o gesto humilde de passagem do alto para o chão humilde onde o poeta descobriu a poesia: da nobreza e frieza heráldica das armas baixa ao mais terreno das emoções, onde o fundo da história cristã da santa ainda reverbera, mas posto a serviço do jogo material e concreto das relações de amor simplesmente humano.

Mas qual o destino da crítica - essa arte sutil e difícil de lidar com o sentido e a qualidade das obras - nos dias de hoje, em que se subestima o prazer da leitura e vão rareando os leitores dos textos difíceis? Que sentido pode ter a exegese minuciosa dos textos, o esforço concentrado da leitura cerrada?

Ninguém desconhece que nosso mundo se tornou pouco literário, que a literatura perdeu decerto o lugar hegemônico que ocupou na cultura do século XIX, ou até a importância que teve entre outras artes nas vanguardas do início do século XX e mesmo depois. Até o romance, gênero moderno por excelência, forma inacabada e voraz, aberta para as novidades do mundo presente parece titubeante nos tempos que correm frente à fragmentação da experiência histórica contemporânea e tende a sucumbir às dificuldades de síntese ou de encontrar uma perspectiva coerente sobre uma matéria que lhe escapa das mãos. Ele mesmo vai se tornando assim um sintoma da perplexidade de nossos dias diante da aparente impossibilidade de criação de obras realmente complexas. 
O próprio destino das chamadas humanidades parece correr enorme risco; a expressão do que há de mais humano no homem tende a se obliterar em face da universalização dos interesses particulares do mercado e da avalanche de mercadorias que ameaçam soterrá-la e se impõem como medida da globalização necessária. As artes duvidam das raízes particulares ou regionais que sempre as nutriram, em nome do universalismo abstrato, levadas pelo ramerrão do sempre igual que as arrasta para o sorvedouro das facilidades comerciais ou da glosa de efeitos do kitsch. Se um presidente de uma nação vem visitar-nos, não cita Machado de Assis, Drummond, Guimarães Rosa ou Clarice, mas Paulo Coelho. A "arte detida e rudimentar da leitura", que Menard, o personagem de Borges, teria enriquecido com a técnica nova dos anacronismos e das atribuições errôneas, parecerá a muitos um arcaísmo em meio aos novos veículos dos textos que disputam espaço com o livro, cujo futuro se julga incerto como o dos jornais, antigos difusores da literatura.

Contudo, a vertiginosa aceleração das mudanças históricas e a voragem abissal que elas podem sugerir a nossos pés não nos devem deixar submergir sob uma sombria onda de pesadelo que faz das transformações um fim com sua sinistra ameaça de apocalipse e a pretensão de nos tragar. Aqui de novo devemos antepor a elas nossa capacidade de invenção e a força de clarividência de nossa consciência crítica, a qual, aparentemente reduzida à dimensão diminuta da relação do leitor com o texto, dá no entanto fundamento e dignidade a nosso trabalho e será sempre a pedra de toque de nossa orientação: a que devemos nos adaptar e a que devemos a todo custo resistir. Contra fatos, sempre haverá argumentos, como nos ensinou Paulo Emílio Salles Gomes em momentos difíceis da ditadura dos anos de 1970.

Em meados do século XIX, Sainte-Beuve, o grande crítico francês, juntou ao terceiro volume de seus Portraits littéraires uma série de "Pensamentos". A certa altura, afirma:

Penso sobre a crítica duas coisas que parecem contraditórias e que não o são:

1. O crítico não é senão um homem que sabe ler e que ensina os outros a ler;

2. A crítica tal qual a entendo e tal como gostaria de praticá-la é uma invenção e uma criação perpétua.

É de dentro dos textos que sempre renasce a invenção da crítica, no fundo uma simples forma inteligente de leitura. Diante do obstáculo, da não-passagem, da situação sem saída, como no "Áporo", de Drummond, a solução, tanto para a poesia quanto para a crítica, encontra-se na força da imaginação, que pode gerar o que pode ser. É cavando humildemente no texto, como o minúsculo inseto do poeta, que o crítico descobre a lógica 
particular e concreta das palavras: o que permite a metaformose do inseto em flor e da flor em poema.

Em nosso tempo, parece que estamos condenados a sentir com mais intensidade e frequência a condição pascaliana de nossa fragilidade e da infinita solidão no universo. Vivemos a todo instante a desconcertante proximidade entre o infinitamente grande e o infinitamente pequeno, uma assombrosa experiência que o poema sempre soube condensar:

Dentro de ti em pequenas pevides

Palpita a vida prodigiosa

Infinitamente.

Acho que podemos todos sentir essa enigmática força da poesia de dizer o todo no mínimo. Nela ainda confio, apesar de todas as perplexidades.

Para um simples agradecimento, levei-os um pouco matreiramente da memória de minha aldeia e do escrutínio de um pequeno texto às vastas dimensões dos problemas de nosso tempo e do universo. Peço-lhes perdão pelas muitas voltas deste discurso que lhes prometia a brevidade.

Não poderia ser diferente, porém, para um discípulo de Ugolino. Não me refiro decerto ao Ugolino de Dante, perdido eternamente nos círculos infernais de sua tragédia, mas a meu Ugolino, caçador elegíaco que viu perder-se intacta no ar a mais bela, a única, a última perdiz de minha terra.

Gostaria de agradecer ainda e por fim a todos os presentes. Aos que vieram de longe, a meus amigos de São João e a meus mais próximos familiares: à minha irmã, que compartilha comigo a paixão dos livros e da leitura, aos meus três enteados que escutam minhas histórias, à minha mulher Laura Janina, metade de mim, querida e constante companheira na longa jornada que temos empreendido pelos países e pelas literaturas da América Latina.

A todos, muitíssimo obrigado pela alegria que me deram.

Davi Arrigucci Jr. formou-se em Letras em 1964, doutorou-se em Teoria Literária e Literatura Comparada em 1972 e tornou-se livre-docente em 1990 pela Universidade de São Paulo. É Professor Emérito da Faculdade de Filosofia, Letras e Ciências Humanas da USP e reconhecido crítico literário e ensaísta brasileiro. Entre suas obras principais estão O escorpião encalacrado: a poética da destruição em Julio Cortázar (1973, 1995, 2003), Humildade, paixão e morte: a poesia de Manuel Bandeira (1990, 2003), Coração partido: uma análise sobre a poesia reflexiva de Drummond (2002), Ugolino e a Perdiz (2003) e Rocambole (2005). Recebeu o Prêmio Jabuti pelo melhor livro de ensaios de 1979, Achados e Perdidos, e o Prêmio APCA de 1987, com Enigma e Comentário. Contato: arriguccijr@uol.com.br 